\title{
Design Quality: A Key Factor to Improve the Product Quality in International Production Networks
}

\author{
Zhu Yanmei ${ }^{1}$, Alard R. ${ }^{2}$ and Schoensleben P. ${ }^{3}$ \\ 1 Tongji University, Academy of Science \& Technology Management, \\ No.1239 Siping Road, 200092 Shanghai, China, \\ Tel:+862165983690, zhu.yanmei@163.com \\ WWW home page: http://sem.tongi.edu.cn \\ 2 ETH Zurich, Center for Enterprise Sciences (BWI), \\ Kreuzplatz 5, 8092 Zurich, Switzerland, \\ Tel:+41 44632 0532, ralard@ethz.ch, \\ WWW home page: http://www.ethz.ch/ \\ 3 ETH Zurich, Center for Enterprise Sciences (BWI), \\ Kreuzplatz 5, 8092 Zurich, Switzerland, \\ Tel:+41446320510,pschoensleben@ethz.ch, \\ WWW home page: http://www.ethz.ch/
}

\begin{abstract}
As the result of the broken-up value chain of the world, design becomes an independent commodity. Goods often are designed in one company and produced in another company. Although product is shaped in manufacturing companies of supply chain, design quality is the key sticking-point for product quality. Therefore, finished goods quality lies on the quality of Design-Manufacturing Chain. This paper defines DesignManufacturing Chain Quality Management (D-MCQM), analyses poor quality of design and manufacturing and the controllable factor and noise factor for quality stability. Furthermore, the figure and formula are presented for the leverage relationship among design quality, manufacturing quality and product quality.
\end{abstract}

\author{
Keywords \\ Design-Manufacturing Chain, Quality Management, Design Quality, \\ Poor Quality, Leverage Relationship
}




\section{Introduction}

With drastic competition from all over the world, the globalization of manufacturing industry, technology complexity increasing, and a strong customer awareness of quality, quality management should be carried out in supply-chain-wide, instead of company-wide. It is indispensable for companies to make the best of resources outside and cooperate with their partners on the supply chain in order to enhance their end-product quality [1]. The cooperation need between the design department and the production department within one company is a well-known topic in practice and research. Nowadays, as the result of the broken-up value chain of the world, technology also becomes an independent commodity [2]. Goods often are designed in one company and produced in another one. Quality management in design and manufacturing phases are not often implemented in a same company, but from the perspective of supply chain. Product quality lies on design and manufacture processes, therefore it is quite significant to study on how to improve product quality by the cooperation between design and manufacture companies from both theoretical and practical sides. This is one of the objectives of the project, Design Chain-Supply Chain-Management (DC-SC-M), focusing the issues between Swiss designers and Chinese suppliers. To be successful in highly competitive global marketplaces where the quality of the designed product is a killer criterion, the designer and manufacturer should improve the end-product quality cooperatively.

\section{Design-Manufacturing Chain ( D-MC)}

From the market demand emerging to finished goods delivery to the end consumer, product goes through several phases from design, manufacturing, transportation, distribution and so on. There into, design phase includes product plan, concept design, detailed design (design specification) and revision, meanwhile manufacturing includes prototyping, test, production plan and full-scale production. DesignManufacturing Chain ( D-MC ) $[3,4]$ is a chain or network made up of design and manufacturing companies, in which the final product is designed and produced within different companies. The simplest form of D-MC consists of only two companies: the designer / designing company (e.g. Original Equipment Manufacturer, OEM) and the manufacturer (manufacturing company).

Manufacturing companies possess know-how on manufacture and assembly which designers usually do not know very well. Therefore, product time-to-market reduction and substantial cost saving from higher productivity, lower maintenance and fewer recalls are the results of Manufacturer Earlier Involvement (MEI) in product design and development stages. Essentially, these are based on the philosophy of Concurrent Engineering ( CE ) [5]. Parts of design and manufacturing process concurrently, rather than sequentially like before. Manufacturing phase can start prototyping and tooling from detailed design phase, not until whole design phase completely finishes (Fig. 1). 


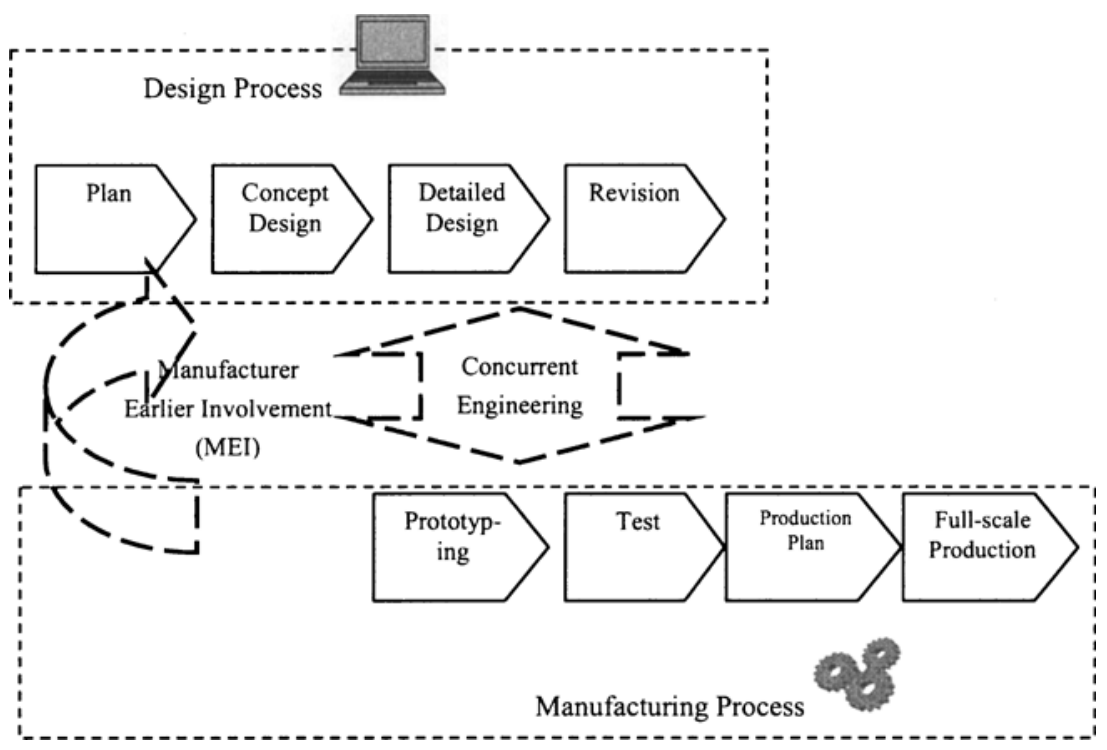

Fig. 1. Design-Manufacturing Chain ( D-MC)

Previous research shows that, while product design may account for only 5 per cent of the product cost, it has a key influence on 75 per cent or more of manufacturing costs, and 80 per cent of quality (Huthwaite B.,1988) [6]. Some have asserted that more than 40 per cent of quality problem stems from design aspect of a product ( Leonard F.W. et al, 1982 ) [7]. Moreover, the product design phase drives 70 to 80 per cent of the final production cost, 70 per cent of life cycle cost of product, and 80 per cent of product quality (Dowlatshahi S., 1992) [8].

Thereby, product design, where drives product "innate" quality, is the key to form product quality, and design phase in D-MC is the most important and potential phase to enhance quality and reduce cost (Fig.2). 


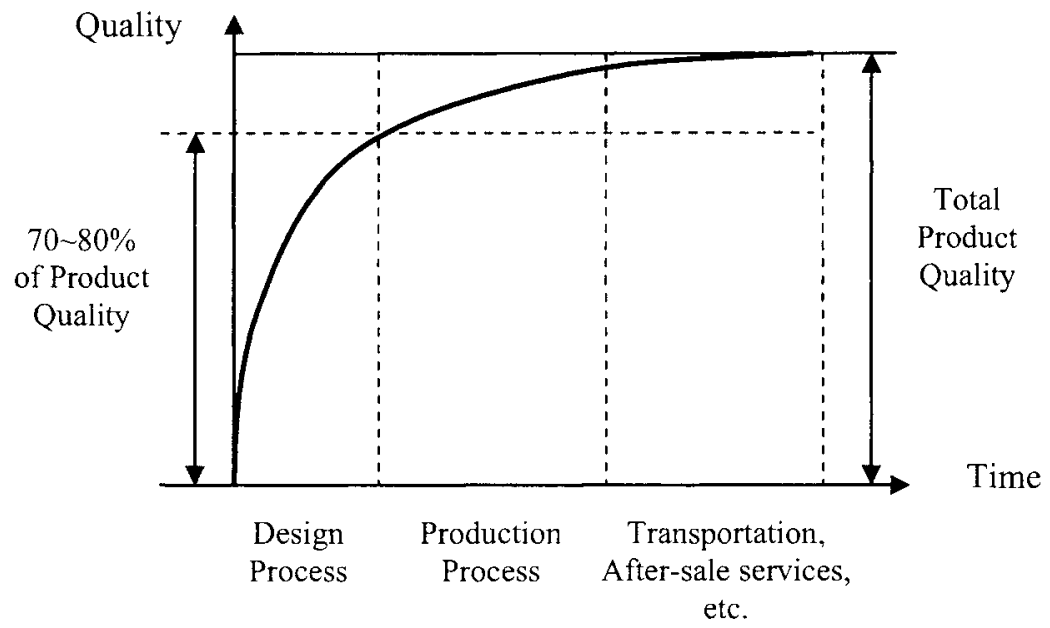

Fig. 2. Incline of Quality

The philosophy of D-MC quality management is controlling product quality from root and focusing on MEI in product design and development, which may accelerate the innovation in manufacturing industry and optimize product quality. D-MC quality management is also based on win-win relationship of supply chain partners. Partners on D-MC think much of quality information/resource sharing about manufacturing, test and so on rather than bargaining.

\section{Design-Manufacturing Chain Quality ( D-MCQ )}

The definition of quality (Crosby, 1986) [9] is conformance to requirement. In design process, quality means that design specification should conform to the requirement of customers, and in manufacturing process, quality means that manufacturing should conform to the design requirement.

Although product quality is related to the level of delivery, after-sale service, maintenance, recyclability, etc, it is mainly shaped in design and manufacturing processes, i.e., product quality depends on D-MC quality.

Based on literature review, desk research and expert interviews involving partners from the design, production and logistics departement in a research project with eight Swiss industrial companies cooperating on an international level, we will demonstrate what the key impact factors for the final product quality are. According to our results these are mainly two factors influencing the final product quality: the design phase of the product (design process) and the manufacturing process itself. Therefore, finished goods quality lies on the quality of Design-Manufacturing Chain. Design-Manufacturing Chain Quality ( D-MCQ) includes two parts, design quality and manufacturing quality. Design quality defines that design requirement may reflect the Voice of Customer (VoC) and demand of market. Manufacturing quality means that end-product conforms to the product design requirement and 
specification, where it is the conformance of quality. If design does not reflect the market requirement, the product can not meet the demand of market even though manufacturing conforms to the design completely, whereas if manufacturing does not conform to the design requirement, the finished product with poor quality can not satisfy customer's needs.

Design-Manufacturing Chain Quality Management (D-MCQM) indicates supervision and controlling the quality of all activities on D-MC. D-MCQM can be depicted by three simple formulae as followed:

Design-Manufacturing Chain $(\mathrm{D}-\mathrm{MC})=$ Chain or network made up of design and manufacturing companies and processes ;

Quality $(\mathrm{Q})=$ Conformance to requirement ;

Management $(M)=$ Activities for improving the design and manufacturing quality.

Poor quality of D-MC includes poor quality of design and poor quality of manufacturing. Poor quality of design means that design requirement has not reflected the demand of customer in right way and/or at right cost and/or at right time. Poor quality of manufacturing means that, manufacturing has not completely conformed to the design requirements/specifications so that the finished product can not satisfy market demand at right cost and right time. Design with technological deficiency resembles inferior product, design changed like the product recalled or returned to production line to be worked again. Apparently, all those are of poor quality.

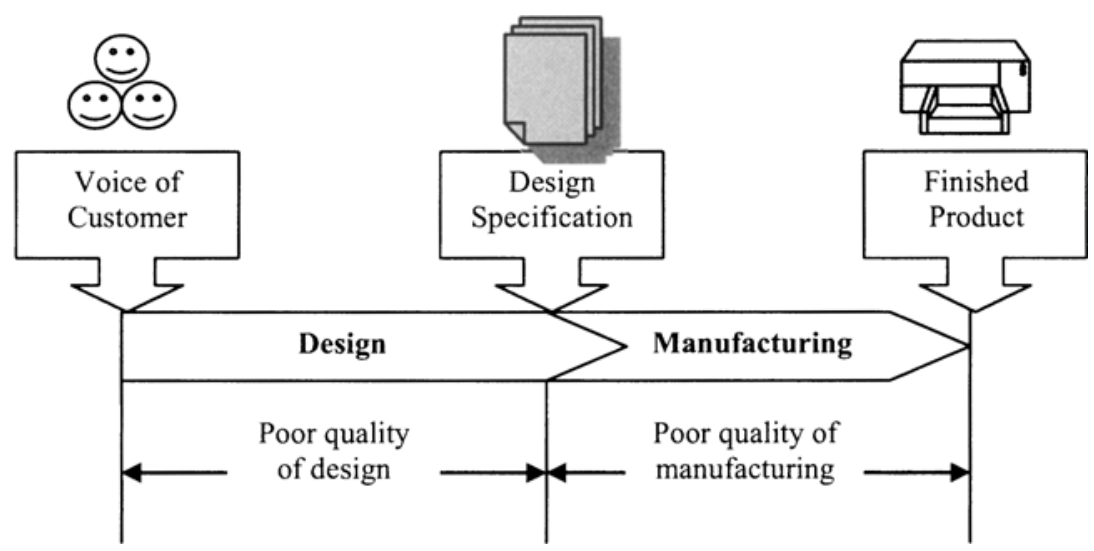

- Fig. 3. Poor Quality of D-MC

Technological deficiency in design, which is "innate" deficiency of product quality, may result in huge quality cost of numerous quality-related maintenance, warranty repair and severe exterior loss [10]. Controlling manufacturing quality usually can not solve the problems which are rooted in design deficiency. Hereby, design quality is decisive to product quality, so in order to gain more customer value 
it is crucial to manage quality starting from design process instead of focusing on manufacturing process only.

An overwhelming majority of product failure costs and design iterations come from the ignorance of noise factors during the early design stage. The noise factors which crop up one by one in the subsequent product delivery stages cause costly failures. Taguchi Method ( TM ) presented by Dr. Taguchi [11] may help designer to select appropriate controllable factors so that the deviation from the ideal is minimized at a low cost. Variation reduction is universally recognized as a key to quality reliability and improvement in D-MC.

The number of controllable factors and noise factors for quality reliability are changed along upstream (design process) and downstream (manufacturing process) of D-MC (Fig.4). Noise factors are uncontrollable in natural condition of use. The noise factors can be divided into three groups: production variations, variations in condition of use, and deterioration. Production variations can be exemplified by change of operators or variations in incoming materials. Furthermore, variations in condition of use can be temperature, air pressure, or air humidity and deterioration by wear or aging of material. From upstream to downstream, controllable factors decreases gradually, but noise factors increases. Accordingly, quality control from root is more efficient than downstream.

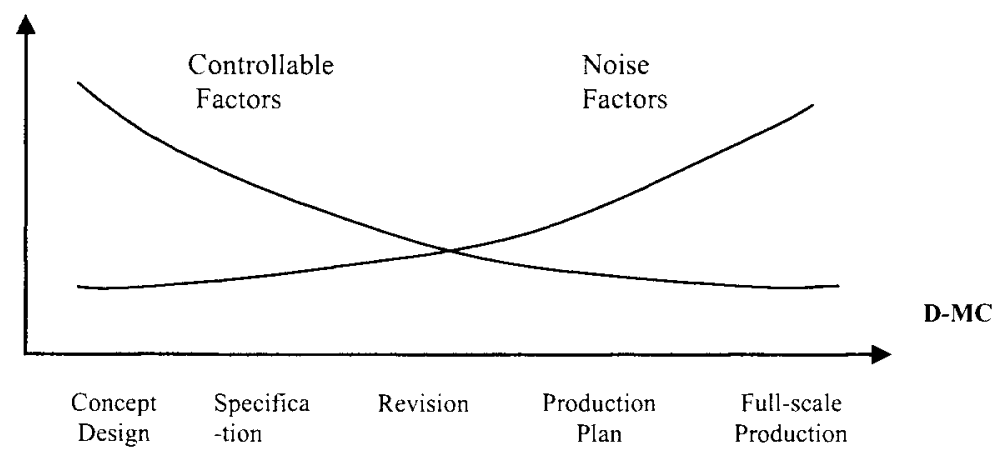

Fig. 4. Controllable Factors and Noise Factors of Quality Stability in D-MC

\section{Leverage Relationship among Design Quality, Manufacturing Quality and Product Quality}

Therefore, to product quality, influence from design is much bigger than from manufacturing. This relationship can be showed with a figure of leverage (Fig.5). 


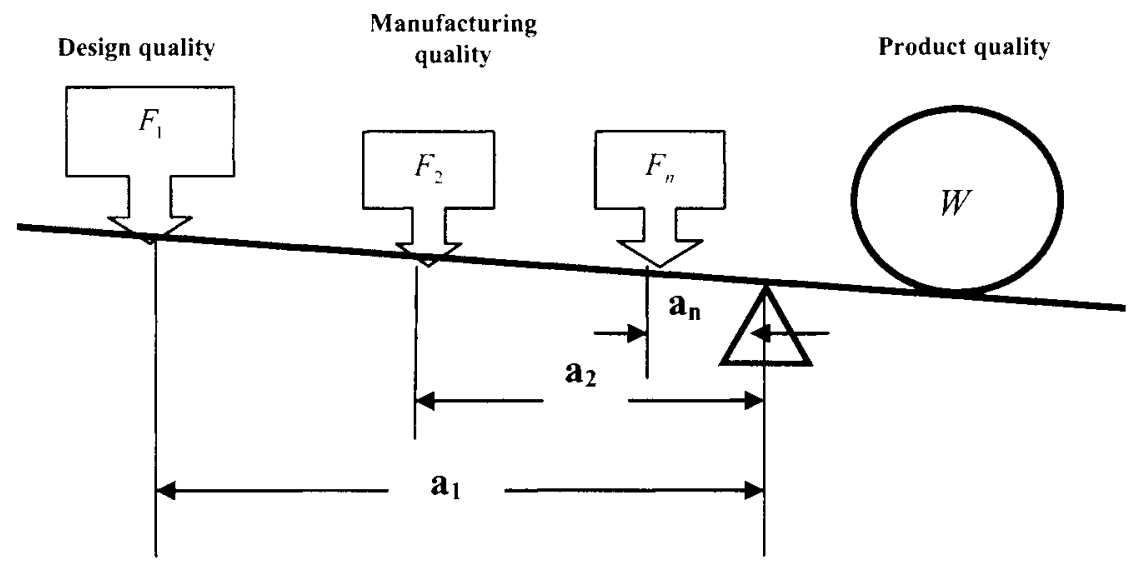

Fig.5. Leverage Relationship among Design Quality, Manufacturing Quality and Product Quality

The followed formula expresses the leverage relationship among design quality, manufacturing quality and final product quality in Fig. 5.

$$
W=F 1 . a 1+F 2 . a 2+\ldots \ldots+F n \cdot a n
$$

Here, $W$ denotes of final product quality. The bigger $W$, the better final product quality;

$F_{1}$ denotes design quality;

$F_{2}$ denotes manufacturing quality ;

$F_{3} \cdots F_{n}$ denote respectively the quality of every other process, e.g. delivery, after-sale service, etc.

$a_{1}$ denotes the extent of influence on final product quality from design quality. According to Fig.2, the extent of influence from design quality is $70 \sim 80$ per cent, then $0.70<a_{1}<0.80$;

$a_{2}$ denotes the extent of influence on final product quality from manufacturing quality. If the extent of influence from design quality is $0.70<a_{1}<0.80$, then $0<a_{2}<0.30$;

Bigger numerical value of $a_{1}, a_{2}$ shows stronger the influence of the process to final product quality.

Surely, other processes quality except design and manufacturing, $F_{3} \cdots F_{n}$, also influence product quality. Their influences are $a_{3} \cdots a_{n}$, respectively. If $F_{1} \cdots F_{n}$ are all of the processes influencing product quality, then $a_{1}+a_{2}+\cdots+a_{n}=1$.

$F_{1} \cdot a_{1}$ and $F_{2} \cdot a_{2}$ respectively express the influence from design quality and manufacturing quality to product quality.

Analysis of the formula shows some ways to enhance product quality:

1. Improving design quality $\left(F_{1}\right)$.

(1) It is imperative that marketing is included as an integral team of design. They are responsible in gather accurate customer requirements for the new product 
development in order to ensure the delivered product meets the customers' expectations.

(2) A collection of tools for design engineering (e.g. QFD, DFMA, Tolerance Analysis, Robust Design, DOE, etc.) should be implemented in product development process in order to avoid huge cost of re-design after product has launched.

(3) To avoid the expensive re-design processes and improve the manufacturability of the design plan, it is necessary to establish a cross-functional team to facilitate Manufacturer Earlier Involvement (MEI) and/or Supplier Early Involvement (SEI) to initiate the product research and development. The crossfunctional team is made up of representatives from such groups as engineering, manufacturing, quality, and supply chain management. Each team member will contribute to specific areas within the product development process.

2. Improving manufacturing quality $\left(F_{2}\right)$.

(1) To enhance the capability to control quality and strengthen manufacturing process to avoid reworking, manufacturers should adopt Advanced Manufacturing Technologies (AMT) such as robotics and Computer-Aided Manufacturing (CAM) and invest in implementing advanced computer-integrated manufacturing applications such as ERP and MRPII to link with other organizational systems.

To offer consistently high quality product and reduce unnecessary cost of rework, two kinds of environmental uncertainty should be paid more attention, one is based on source scarcity and the other based on information complexity.

\section{Conclusion}

D-MCQ includes two parts, design quality and manufacturing quality. Whereas product is shaped in manufacturing process, product quality stems from design process. In the upstream of D-MC (design process), quality is managed more efficiently due to more controllable factors and less noise factors. The figure of leverage and its formula show clearly the relationship among design duality, manufacturing quality and product quality. Moreover, they direct managers responsible of quality to turn their attention to design process, instead of keeping their eyes on manufacturing all the time. In a whole, to optimize product quality, it is crucial to successfully manage D-MCQ by collaboration of the partner companies on the whole D-MC.

This paper addresses especially industrial practitioners from design and production departements in supply chains. We show the importance of the interaction and organizational cooperation between the design departement and the production departement of different companies in supply chain, especially in international supply chains. The outcome of the paper can be used to sensitise the different actors / practitioners in the industrial companies towards the importance of the coordination between the different involved actors and the relationship between the product quality and the design process (design phase) based on a general and comprehensible model. 


\section{Reference}

1. Kesheng Wang, George Kovacs, Michael Wozny and Minghun Fang, Knowledge Enterprise: Intelligent Strategies in Product Design, Manufacturing, and Management, SV, 2006.

2. Guo, Chongqing., Strategy for improving innovation and marketing capabilities of China, Proceeding of China Mechanical Engineering Acad., 2006(1): 6-12.

3. Zhu Yanmei., Wu Xiaojun, and You Jianxin., Research on the Design Manufacturing Chain Model Under the Globalization of Manufacturing Industry, Development and Management, Shanghai People Press, Shanghai, 2006: 86-93.

4. Zhu, Yanmei, and Alard, R., Shaping the Design-Manufacturing Interface between Swiss Design Department and Chinese Manufacturer, Journal of Tongji University (Natural Science), 2005(9): 10-15.

5. Schoensleben, P., Integral Logistics Management-Planning and Control of Comprehensive Supply Chains (Second Edition), St. Lucie Press, 2003:258-259.

6. Huthwaite, B., Designing in Quality, Quality, 1988, Vol.27 No. 11, 34-50.

7. Leonard, F.W. and Sasser, W.E., The Incline of Quality, Harvard Business Review, 1982(60):163-171.

8. Dowlatshahi, S., Purchasing's role in a concurrent engineering environment, International Jounal of Purchasing and Material Management, 1992, Winter, pp2125.

9. Philip B. Crosby, Quality Without Tear: The Art of Hassle-Free Management, McGraw-Hill, New York, 1984:58-86.

10. You Jianxin and Guo Chongqing, Quality Cost Management, Pertroleum Industrial Press. 2003.

11. Taguchi, G., Elsayed, E., and Hsiang, T., Quality Engineering in Production Systems, McGraw-Hill, New York, NY,1989. 